\title{
Treatment of Diabetic Foot Infections: A Prospective Study Highlighting the Efficacy and Safety of Moxifloxacin
}

\author{
Bikha Ram Devrajani ${ }^{a}$, Samar Raza ${ }^{\mathrm{b}}$, Rubina Khushik ${ }^{\mathrm{a}}$, Syed Zulfiquar Ali Shah ${ }^{\mathrm{b}}$, \\ Sanam Mari ${ }^{\mathrm{a}}$, Sindhu Lagharia ${ }^{\mathrm{a}}$, Neeta Maheshwary ${ }^{\mathrm{c}, \mathrm{d}}$
}

\begin{abstract}
Background: Foot infection involving the skin, soft tissues and bony structures, is a common complication of foot ulcers in diabetic individuals and represents a major cause of morbidity and mortality. Systemic antibiotic treatment must be given as early as possible initially on empirical basis and based on the response to empirical therapy and wound culture and sensitivity results, definitive therapy should be decided. This study was conducted to assess the efficacy and safety of moxifloxacin for treating diabetic foot infections in Pakistani population.
\end{abstract}

Methods: After taking ethical approval, an interventional phase IV study was conducted in the department of medicine and diabetic clinic, Liaquat University Hospital, Jamshoro, Hyderabad from March 2017 till August 2017. A total of 75 patients with diabetic foot infection who were sensitive to moxifloxacin on culture and sensitivity were included in the study using non-probability convenient sampling technique. All the demographic and clinical information was collected by using a questionnaire specially designed for the study. After making clinical assessment, all the patients were treated with sequential intravenous/oral moxifloxacin for 14 days. Bacteriologic response was based on the results of cultures of specimens of infected skin or soft tissue or blood. The data were analyzed on SPSS version 20.0. Chi-square test was used with significant level set at 0.05 .

Results: The study results revealed that the majority of patients with diabetic foot ulcer were males with the age of greater than 45 years. Only $21.3 \%$ of them had a comorbidity, either hypertension alone or hypertension with ischemic heart disease, whereas $84 \%$ of them reported their foot ulcers to be cured at the end of treatment. Furthermore, only younger age was found to have a significant positive

Manuscript submitted January 25, 2018, accepted February 8, 2018

aLiaquat University of Medical and Health Sciences, Jamshoro, Pakistan bepartment of Medicine, Liaquat University Hospital Hyderabad, Hyderabad, Pakistan

${ }^{c}$ Medical Department, Senior Manager Medical Affairs \& Clinical Research, Hilton Pharma PVT Ltd, Progressive Plaza, Beaumont Road, Karachi, Pakistan ${ }^{\mathrm{d} C o r r e s p o n d i n g ~ A u t h o r: ~ N e e t a ~ M a h e s h w a r y, ~ S e n i o r ~ M a n a g e r ~ M e d i c a l ~ A f f a i r s ~}$ \& Clinical Research, Hilton Pharma PVT Ltd, Progressive Plaza, Beaumont Road, Karachi, Pakistan. Email: drneeta@hiltonpharma.com

doi: https://doi.org/10.14740/jem485w association with healing of foot ulcers.

Conclusions: Moxifloxacin is effective in treating diabetic foot infections and $84 \%$ of the diabetic patients in the present study reported the healing of foot ulcers as a result of a 2 -week moxifloxacin treatment. Further evaluation of the role of moxifloxacin in the treatment of diabetic foot ulcer is recommended.

Keywords: Clinical trial; Safety and efficacy; Moxifloxacin; Diabetic foot infections

\section{Introduction}

Foot infection involving the skin and soft tissues and/or bony structures, is a common complication of foot ulcers in diabetic individuals and represents a major cause of morbidity and mortality [1-3]. It is estimated to be the most common cause of diabetes-related admission to hospital and remains one of the major reasons for lower-limb amputation [4-6]. Systemic antibiotic treatment must be given as early as possible for diabetic foot infections (DFIs), initially on an empirical basis [7-9]. Based on the response to empirical therapy and wound culture and sensitivity results, definitive therapy should be decided [10]. The estimated lifetime risk of a person with diabetes mellitus developing a foot ulcer is $15 \%$ to $25 \%$, with an annual incidence of $3 \%$ to $10 \%$ [11]. Major predisposing factors are peripheral neuropathy, peripheral arterial disease, and impaired immunity [12]. More than one-half of non-traumatic lower extremity amputations are related to DFIs, and $85 \%$ of all lower extremity amputations in patients with diabetes are preceded by an ulcer [13]. DFIs cause morbidity, limit mobility, predispose to depression and worsen patients' quality of life.

The most common pathogens in DFI are aerobic grampositive cocci, mainly Staphylococcus species. Methicillinresistant Staphylococcus aureus is present in $10 \%$ to $32 \%$ of diabetic infections and is associated with a higher rate of treatment failure in patients with DFI [13]. Moderate to severe infections and wounds previously treated with antibiotics are often polymicrobial, including gram-negative bacilli. Anaerobic pathogens are more commonly present in necrotic wounds and infections of the ischemic foot [12]. In the past 20 years, various fluoroquinolone agents have been used successfully for 
Table 1. Age of Participants in the Study (Years)

\begin{tabular}{ll}
\hline Mean & 45.29 \\
Median & 44 \\
Standard deviation & 6.57 \\
Minimum & 35 \\
Maximum & 65 \\
\hline
\end{tabular}

treating DFIs. Moxifloxacin is a newer fluoroquinolone with activity against most aerobic and anaerobic gram-positive and gram-negative bacteria; it is currently approved for the treatment of complicated skin and skin structure infections caused by designated susceptible pathogens, but not specifically for DFI [13].

This study therefore was carried out to assess the efficacy and safety of moxifloxacin for treating DFIs in Pakistani population so that if proven efficacious and safe, it can be recommended to be added in the treatment algorithm of DFIs specifically.

\section{Materials and Methods}

After taking ethical approval, an interventional phase IV study was carried out in the department of medicine and diabetic clinic, Liaquat University Hospital, Jamshoro, Hyderabad. The duration of study was from March 2017 till August 2017. A total of 75 patients with DFI who were sensitive to moxifloxacin on culture and sensitivity were included in the study through convenient sampling technique after seeking their informed consent. Patients willing to undergo screening, belonging to either gender, aged 18 or above, with any foot infection with a history of diabetes or any foot infection with a documented foot ulcer with a history of diabetes, and with at least three of the following signs or symptoms of wound infection were included in the study: drainage or discharge, erythema, fluctuance, localized heat or warmth, pain or tenderness, swelling or induration, fever, leukocytosis or $15 \%$ immature neutrophils on peripheral blood smear. Patients with human immunodeficiency virus (HIV), vasculitis, connective tissue disorders, received antibiotic therapy for $24 \mathrm{~h}$ within last 3 days or needed concomitant systemic antibiotic therapy for treatment of other infections, a DFI with suspected or documented osteomyelitis, unless the infected bone was fully or partially resected and any residual soft tissue infection could be adequately treated with study drug for 14 days, major learning barriers such as visual or hearing impairment or dementia, history of arthritis or history of cardiac arrhythmias including prolonged QT were excluded from the study.

All the demographic and clinical information was collected by using a questionnaire specially designed for the study. After making clinical assessment, all the patients were treated with sequential intravenous/oral moxifloxacin for 14 days. Clinical assessments were made prior to antibiotic therapy, and at the end of therapy on the 14th day. Clinical response was defined as cure when resolution of all acute signs and symptoms related to the infection or sufficient improvement such
Table 2. Participants Profile

\begin{tabular}{|lll|}
\hline Variables $(\mathbf{n}=\mathbf{7 5})$ & Frequency & Percentage \\
\hline $\begin{array}{l}\text { Gender } \\
\quad \text { Male }\end{array}$ & 46 & $61.3 \%$ \\
$\quad$ Female & 29 & $38.7 \%$ \\
\hline $\begin{array}{l}\text { Age groups } \\
\quad \leq 45 \text { years old }\end{array}$ & \\
$\quad>45$ years old & 22 & $29.3 \%$ \\
Comorbidity & 53 & $70.7 \%$ \\
$\quad$ Hypertension & & \\
$\quad$ Hypertension and IHD & 3 & $17.3 \%$ \\
$\quad$ None & 59 & $4 \%$ \\
Foot ulcer cured & & $78.7 \%$ \\
$\quad$ Yes & 63 & $84.0 \%$ \\
$\quad$ No & 12 & $16.0 \%$ \\
\hline
\end{tabular}

IHD: ischemic heart disease.

that additional antimicrobial therapy not required and failure was defined as insufficient resolution of the signs and symptoms of acute infection, necessitating additional or alternative antimicrobial therapy. Bacteriologic response was based on the results of cultures of specimens of infected skin or soft tissue or blood. The bacteriologic response was categorized as confirmed eradication (if all of the original pathogens are absent from a post-baseline specimen); presumed eradication (if there was no post-baseline culture but the patient had clinically responded to study therapy); persistence (presence of a baseline pathogen in a post-baseline specimen from a tissue biopsy or needle aspiration of fluid contiguous to the primary infected area in a patient who failed clinical therapy, or from blood); or indeterminate (inability to determine the bacteriologic response to treatment).

The data were entered and analyzed on SPSS version 20.0. Means and standard deviations were calculated for continuous variables whereas frequencies and percentages were generated for categorical variables. Chi-square test was applied to check for associations and the significance level was set at 0.05 .

\section{Results}

The study results revealed that the mean age of the study participants was $45.29 \pm 6.57$ years with the range being from 35 to 65 years (Table 1). Totally $61.3 \%$ of them were males whereas $70.7 \%$ of them belonged to $>45$ years age group. Only $17.3 \%$ of them had hypertension as comorbidity whereas $4 \%$ of them had both hypertension and ischemic heart disease. About $84 \%$ of them reported their foot ulcers to be cured at the end of treatment (Table 2; Fig. 1).

The study results further revealed that among gender, age and comorbidity, only age had a statistically significant association with healing of foot ulcers $(\mathrm{P}=0.002)$ where patients who belonged to $\leq 45$ years age group were more likely to 


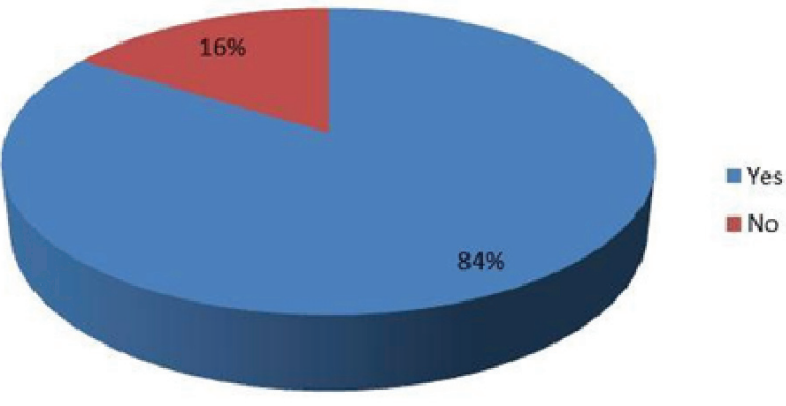

Figure 1. Cure of foot ulcer.

have their foot ulcers cured than those who belonged to $>45$ years age group (66.7\% vs. 33.3\%) (Table 3$)$.

\section{Discussion}

The study results revealed that the majority of patients with diabetic foot ulcer were males and $>45$ years old. Only $21.3 \%$ of them had a comorbidity, either hypertension alone or hypertension with ischemic heart disease, whereas $84 \%$ of them reported their foot ulcers to be cured at the end of treatment. Furthermore, among gender, age and comorbidity, only age was found to have a significant association with healing of foot ulcers where younger patients were more likely to have their foot ulcers cured than the older ones.

A majority of the patients with diabetic foot ulcer in the study were males. Likewise, foot ulcers have been reported earlier to develop more frequently in males $(P<0.001)$ [14]. Contrary findings have been reported though, with an earlier study finding the prevalence of diabetic peripheral neuropathy, the cause of subsequent foot ulcers, to be similar in both genders [15]. This difference in findings could be attributed to different study methodologies of both studies.

Interestingly, and as expected, a majority of the patients with diabetic foot ulcer belonged to older age groups. Similarly, old age has been reported earlier to be a risk factor for development of diabetic foot ulcer $(\mathrm{P}<0.001)$ [16]. Another study found age to be an independent predictor of foot ulceration in diabetic patients $(\mathrm{P}<0.01)$ [17]. Literature though reports dissimilar findings as well [14]. This difference in findings could be due to different population characteristics of both the studies.

Gender was not found to be significantly associated with wound healing in this study. Likewise, an earlier meta-analysis also reported gender to be unassociated with the probability of wound healing $(\mathrm{OR}=1.02$; 95\% CI, 0.69 - 1.50) [18]. Moreover, the study results found younger age to be positively associated with wound healing. However, literature reported contrary findings with age of the patients reported to be unassociated with the probability of wound healing [18]. This difference in findings could be due to smaller sample size of this study.

The Infectious Diseases Society of America recommends an initial antibiotic course of 1 - 2 weeks for mild soft tissue infections and 2 - 3 weeks for moderate to severe soft tissue infections [3]. In this study, $84 \%$ of the patients had their foot ulcers healed by the end of 14-day treatment with moxifloxacin. This finding was highly suggestive of the efficacy of moxifloxacin in the treatment of DFIs. An earlier clinical trial reported intravenous and/or oral moxifloxacin to be as effective as intravenous piperacillin-tazobactam and/or amoxicillin-clavulanate in treating moderate to severe DFIs with similar clinical cure rates $(68 \%$ vs. $61 \%)$ thereby indicating the potential of moxifloxacin as a monotherapy regimen for such infections [19]. Another clinical trial reported similar overall bacteriological success rates in groups of patients treated with intravenous/ oral moxifloxacin or intravenous piperacillin-tazobactam followed by oral amoxicillin-clavulanate $(71.7 \%$ vs. $71.8 \%)$ for DFIs [20]. Moxifloxacin has also been shown to exhibit good to excellent antimicrobial activity against most aerobic and anaerobic microorganisms in surgical isolates from patients with intra-abdominal infections and DFIs [21].

The qualitative approach of this study has assured that we have assessed the wide range of patients and their response to the treatment. Nevertheless, the study might not be immune from selection and observer bias. Considering the views and observations of this study and to what extend it would be consistent with the other antibiotic therapies would be revealing to discover more facts about the effective treatment in patients with DFIs.

Table 3. Association of Participants' Characteristics With Healing of Foot Ulcer

\begin{tabular}{|c|c|c|c|}
\hline \multirow{2}{*}{ Variables $(n=75)$} & \multicolumn{2}{|c|}{ Foot ulcer } & \multirow{2}{*}{ P value } \\
\hline & Cured frequency $(\%)$ & Not cured frequency $(\%)$ & \\
\hline \multicolumn{4}{|l|}{ Gender } \\
\hline Female & $23(36.5)$ & $6(50.0)$ & \\
\hline \multicolumn{4}{|l|}{ Age group } \\
\hline \multicolumn{4}{|l|}{ Comorbidity } \\
\hline None & $51(81.0)$ & $8(66.7)$ & 0.228 \\
\hline Hypertension and IHD & $12(19.0)$ & $4(33.3)$ & \\
\hline
\end{tabular}




\section{Conclusions}

Moxifloxacin is effective in treating DFIs and $84 \%$ of the diabetic patients in the present study reported the healing of foot ulcers as a result of a 2-week moxifloxacin treatment. Further evaluation of the role of moxifloxacin in the treatment of diabetic foot ulcer is recommended.

\section{Limitation}

Due to resources constraints, the study could not be conducted with a larger sample size and using a random sampling technique. In light of the study findings, it is recommended that the role of moxifloxacin in the treatment of diabetic foot ulcer is worth evaluating further as an exceedingly high majority of the patients reported their foot ulcers healed as a result of moxifloxacin treatment in this study.

\section{Acknowledgments}

The authors recognize all investigators at the participating centers and all patients for their assurance to the study. All authors contributed in the data gathering, improvement and writing of the manuscript and take full accountability for the content of the article. Authors thank Dr. Adnan Anwar, medical research consultant (The Research Professional Services Ltd), for drafting and reporting support. All authors read and delivered final endorsement of the narrative to be published. Furthermore, all authors take the responsibility of complete features of the study and assure that the doubts related to the accuracy of any portion of the work are properly discovered with devotion.

\section{Disclosure}

Professor Dr. Bikha Ram as the principle investigator had full access to all of the data in the study and takes responsibility for the integrity of the data and the accuracy of the data analysis, including adverse effects.

\section{Conflict of Interest}

Hilton Pharma Pvt Ltd was involved in organizing, evaluating and interpretation of the data with writing of the manuscript. NM is full-time employees of Hilton Pharma Pvt ltd. The writers project no encounters of interest. The morality of the revision was not operated for any financial assistance. Furthermore, the observers were provided with the reward for their involvement in examination of the patients and data entry during the study period.

\section{Financial Support}

The financial assistance was provided by Hilton Pharma Pvt
Ltd, that delivered the medicine and the amount of the laboratory tests completed throughout the intervention.

\section{References}

1. Lavery LA, Armstrong DG, Wunderlich RP, Tredwell J, Boulton AJ. Diabetic foot syndrome: evaluating the prevalence and incidence of foot pathology in Mexican Americans and non-Hispanic whites from a diabetes disease management cohort. Diabetes Care. 2003;26(5):14351438.

2. Lipsky BA, Berendt AR, Deery HG, Embil JM, Joseph WS, Karchmer AW, LeFrock JL, et al. Diagnosis and treatment of diabetic foot infections. Clin Infect Dis. 2004;39(7):885-910.

3. Lipsky BA, Berendt AR, Cornia PB, Pile JC, Peters EJ, Armstrong DG, Deery HG, et al. 2012 Infectious Diseases Society of America clinical practice guideline for the diagnosis and treatment of diabetic foot infections. Clin Infect Dis. 2012;54(12):e132-173.

4. Lavery LA, Armstrong DG, Murdoch DP, Peters EJ, Lipsky BA. Validation of the Infectious Diseases Society of America's diabetic foot infection classification system. Clin Infect Dis. 2007;44(4):562-565.

5. Daum RS. Clinical practice. Skin and soft-tissue infections caused by methicillin-resistant Staphylococcus aureus. N Engl J Med. 2007;357(4):380-390.

6. Lipsky BA, Peters EJ, Senneville E, Berendt AR, Embil JM, Lavery LA, Urbancic-Rovan V, et al. Expert opinion on the management of infections in the diabetic foot. Diabetes Metab Res Rev. 2012;28(Suppl 1):163-178.

7. Reiber GE, Vileikyte L, Boyko EJ, del Aguila M, Smith DG, Lavery LA, Boulton AJ. Causal pathways for incident lower-extremity ulcers in patients with diabetes from two settings. Diabetes Care. 1999;22(1):157-162.

8. Boulton AJ, Vileikyte L, Ragnarson-Tennvall G, Apelqvist J. The global burden of diabetic foot disease. Lancet. 2005;366(9498):1719-1724.

9. Frykberg RG. A summary of guidelines for managing the diabetic foot. Adv Skin Wound Care. 2005;18(4):209214.

10. Peters EJ, Lipsky BA. Diagnosis and management of infection in the diabetic foot. Med Clin North Am. 2013;97(5):911-946.

11. Daniel R. Once-daily oral trovafloxacin in the treatment of diabetic foot infections. Drugs. 1999;58:291-292.

12. Keating GM, Scott LJ. Moxifloxacin: a review of its use in the management of bacterial infections. Drugs. 2004;64(20):2347-2377.

13. Giordano P, Song J, Pertel P, Herrington J, Kowalsky S. Sequential intravenous/oral moxifloxacin versus intravenous piperacillin-tazobactam followed by oral amoxicillin-clavulanate for the treatment of complicated skin and skin structure infection. Int J Antimicrob Agents. 2005;26(5):357-365.

14. Pham H, Armstrong DG, Harvey C, Harkless LB, Giurini JM, Veves A. Screening techniques to identify people at high risk for diabetic foot ulceration: a prospective multi- 
center trial. Diabetes Care. 2000;23(5):606-611.

15. Young MJ, Boulton AJ, MacLeod AF, Williams DR, Sonksen PH. A multicentre study of the prevalence of diabetic peripheral neuropathy in the United Kingdom hospital clinic population. Diabetologia. 1993;36(2):150154.

16. Shahi SK, Kumar A, Kumar S, Singh SK. Prevalence of diabetic foot ulcer and associated risk factors in diabetic patients from North India. Age. 2012;47(8):55-26.

17. Abbott CA, Vileikyte L, Williamson S, Carrington AL, Boulton AJ. Multicenter study of the incidence of and predictive risk factors for diabetic neuropathic foot ulceration. Diabetes Care. 1998;21(7):1071-1075.

18. Margolis DJ, Kantor J, Santanna J, Strom BL, Berlin JA. Risk factors for delayed healing of neuropathic diabetic foot ulcers: a pooled analysis. Arch Dermatol. 2000;136(12):1531-1535.
19. Lipsky BA, Giordano P, Choudhri S, Song J. Treating diabetic foot infections with sequential intravenous to oral moxifloxacin compared with piperacillin-tazobactam/amoxicillin-clavulanate. J Antimicrob Chemother. 2007;60(2):370-376.

20. Schaper NC, Dryden M, Kujath P, Nathwani D, Arvis P, Reimnitz P, Alder J, et al. Efficacy and safety of IV/PO moxifloxacin and IV piperacillin/tazobactam followed by PO amoxicillin/clavulanic acid in the treatment of diabetic foot infections: results of the RELIEF study. Infection. 2013;41(1):175-186.

21. Edmiston CE, Krepel CJ, Seabrook GR, Somberg LR, Nakeeb A, Cambria RA, Towne JB. In vitro activities of moxifloxacin against 900 aerobic and anaerobic surgical isolates from patients with intra-abdominal and diabetic foot infections. Antimicrob Agents Chemother. 2004;48(3):1012-1016. 